\title{
Total Hip Arthroplasty after Failed Internal Fixation of Neck Femur Fracture: Analysis of 12 Cases
}

Khaled Mohammed Hassan, Elsayed Eletewy Soudy, Mohamed Mansour Elzohairy, Ahmed Mohammed Fathy Atia*

Department of Orthopedic Surgery, Faculty of Medicine, Zagazig University

*Corresponding author: Ahmed Mohammed Fathy Atia, Mobile: (+20) 01067563576, E-Mail: drahmed9250@gmail.com

\begin{abstract}
Background: There are different indications for total hip arthroplasty (THA) after failed internal fixation of neck femur fracture. This led us to carry out a prospective study of the clinical outcomes, radiological outcomes, technical issues and complications of this procedure.

Objective: To evaluate the clinical and radiological outcome of total hip arthroplasty after failed internal fixation of neck femur fracture, along with the technical difficulties and complications encountered.

Patients and methods: This was a prospective, single-center study of 12 THA cases performed after internal fixation of neck femur fracture. These procedures were performed between 2017 and 2019 in 12 patients (5 men, 7 women). The initial fracture fixation involved a screw-plate $(n=1)$, intramedullary nail $(n=2)$ or screws $(n=9)$. The mean patient age at the time of THA was 50 years [38-72]. The THA was performed an average of 2.8 years [0.2-28] after the fracture. The lateral (Modified Hardinge) hip approach was used in all cases. 3 patients $(25 \%)$ had the fixation hardware removed before the THA procedure. During the THA procedure, a cemented stem was used in 4 cases (33.3\%) and a cement less stem in 8 cases (66.7\%). A cement less press-fit cup was used in all cases.
\end{abstract}

Results: No patients were lost to follow-up. Two patients suffered an intraoperative femur fracture (16.7\%) and one suffered a dislocation (8.3\%). One hip had to be reoperated $(8.3 \%)$ and required an implant change. With a mean follow-up of 36 months [12-48], the mean modified Harris hip score was 78.2 \pm 4.4 [35-91]. Conclusion: THA is a satisfactory salvage procedure after failed internal fixation of neck femur fracture. Keywords: Total Hip Arthroplasty, Internal Fixation, Neck Femur Fracture.

\section{INTRODUCTION}

Fractures of the proximal aspect of the femur are becoming more prevalent as the population ages. Femoral neck (intracapsular) and intertrochanteric (extracapsular) fractures account for most of these fractures. Although the treatment of these two common injuries differs, the salvage procedure for failed internal fixation often includes conversion to total hip arthroplasty (THA) ${ }^{(1)}$. The treatment of femoral neck fractures has traditionally included either internal fixation in the form of cannulated screws/pins or acute arthroplasty in the form of hemiarthroplasty or THA ${ }^{(2,3)}$. The use of internal fixation for neck femur fractures can fail secondary to nonunion, loss of fixation, femoral head osteonecrosis, posttraumatic arthritis, infection, or symptomatic hardware ${ }^{(4)}$.

The aim of the work was to evaluate the clinical and radiological outcome of total hip arthroplasty after failed internal fixation of neck femur fracture, along with the technical difficulties and complications encountered. We hypothesized that THA is a valuable procedure for management of failed internal fixation of neck femur fracture.

\section{PATIENT AND METHODS}

This was a prospective, single-center study of all THA cases performed following internal fixation of neck femur fracture between August 2017 and September 2019. Patients who underwent hemiarthroplasty were excluded. We included 12 secondary THA cases ( 5 men, 7 women). The mean age at the time of presentation was 60 years [38-69].

The THA procedure was carried out within an average of 8 years [1-20] after the initial fracture fixation procedure. The lateral (modified Hardinge) hip approach was used in all cases. Three patients $(25 \%)$ had the fixation hardware removed before the THA procedure, while the 9 other patients $(75 \%)$ had their fixation hardware removed at the time of THA.

For the THA procedure, cemented stems were used in 4 cases $(33.3 \%)$ and cementless ones in 8 cases $(66.7 \%)$, all were standard length except for two long cementless stems. A cementless cup was used in all cases (Table 3). A metal-polyethylene (Me$\mathrm{PE})$ bearing was used in 10 cases $(83.3 \%)$ and a ceramic-ceramic (C-C) bearing in 2 cases (16.7\%).

\section{Assessment methods}

Clinical and radiographic assessments were carried out. The estimated blood loss and procedure time were calculated. The modified Harris Hip ${ }^{(5)}$ score was used to assess patient function. Radiographs were used to determine the 
implant position and to look for radiolucent lines, ectopic ossification (according to Brooker et al. ${ }^{(6)}$ and cement leakage around cemented stems. The stem was labeled as being in varus or valgus if there was $5^{\circ}$ or more difference between the stem axis and the femur's anatomical axis. Subsidence of the stem was evaluated on an AP view of the pelvis by measuring the distance between the tip of the greater trochanter and the center of the replacement of the femoral head and comparing it to the contralateral, healthy hip. The stem was labeled as suspended (too high) or sunk down (too low) if the difference was $\geq 1 \mathrm{~cm}$.

\section{Ethical and patients' approval:}

An approval of the study was obtained from Zagazig University academic and ethical committee. Every patient signed an informed written consent for acceptance of the operation.

Statistical methods:

The collected data were computerized and statistically analyzed using SPSS program (Statistical Package for Social Science) version 16.0. Qualitative data were represented as frequencies and relative percentages. Quantitative data were expressed as mean \pm SD (Standard deviation). Chi square test $(\chi 2)$ or Fisher's exact test was used to calculate difference between qualitative variables. Student $t$ test was used to calculate difference between quantitative variables. The results considered significant when the Probability ( $\mathrm{P}$ value) was equal or less than 0.05 , highly significant if it was less than 0.01 and very highly significant if it was less than 0.001 .

\section{RESULTS}

The mean procedure time was 65 minutes [60-150]). The mean blood loss was $1250 \mathrm{ml} \mathrm{[250-}$ 2000].

Three types of internal fixation techniques were used: dynamic hip screw (DHS), intramedullary locked nail and cannulated screws (Table 1).

Table (1): Internal fixation methods used with the initial proximal femur fractures

\begin{tabular}{|l|c|c|c|c|c|}
\hline & $\begin{array}{c}\text { Screw } \\
\text { fixation }\end{array}$ & DHS & DCS & $\begin{array}{c}\text { Intramedullary } \\
\text { nailing }\end{array}$ & $\begin{array}{c}\text { Proximal } \\
\text { femur locked } \\
\text { plate }\end{array}$ \\
\cline { 2 - 6 } & $\mathbf{N ~ ( \% )}$ & $\mathbf{N ~ ( \% )}$ & $\mathbf{N ~ ( \% )}$ & $\mathbf{N}(\%)$ & N (\%) \\
\hline $\begin{array}{l}\text { Intracapsular } \\
\text { fracture (N=12) }\end{array}$ & $9(75)$ & $1(8.33)$ & $0(0)$ & $2(16.67)$ & $0(0)$ \\
\hline
\end{tabular}

The main indication for secondary THA was avascular necrosis $(58.33 \%)$ and failure of the fixation hardware (33.33\%) (Table 2).

Table (2): Secondary THA indications.

\begin{tabular}{|l|c|c|c|c|c|}
\hline & AVN & $\begin{array}{c}\text { Non } \\
\text { union }\end{array}$ & Infection & $\begin{array}{c}\text { Hardware } \\
\text { failure }\end{array}$ & P value \\
\cline { 2 - 6 } & $\mathbf{N ~ ( \% )}$ & $\mathbf{N}(\%)$ & $\mathbf{N ~ ( \% )}$ & $\mathbf{N}(\mathbf{\%})$ & \\
\hline $\begin{array}{l}\text { Intracapsular } \\
\text { fracture (N=12) }\end{array}$ & $7(58.33)$ & $0(0)$ & $1(8.33)$ & $4(33.33)$ & $\begin{array}{c}<0.001 £ \\
(\mathrm{HS})\end{array}$ \\
\hline
\end{tabular}

Table (3) showed that one patient suffered from an intraoperative femur fracture $(8.3 \%)$. The postoperative complications consisted of one case of dislocation. This case underdone revision by cementless long stem femoral component. There were no infections or periprosthetic fractures.

None of the patients were lost to follow-up. The mean follow-up was 20 months [12-36] for the entire cohort, with no significant difference between groups. The mean modified Harris Hip score was 78.2. At the final follow-up, 7 patients said that they were completely pain-free after the THA procedure, while 5 patients had hip pain.

The mean cup inclination was $43.5^{\circ}$ [30-60]. There were no instances of full radiolucent lines. In all cases the position of the femoral stem on an AP view was seen in neutral alignment with the longitudinal axis of the femoral shaft and the tip situated in the centre of the shaft. No full or progressive radiolucent lines or signs of stem migration were seen on the radiographs. None of the patients had ectopic ossifications. The intraoperative fractures had healed by the time of the final follow-up. 
Table (3): Socio demographic characteristics of the studied patients and outcomes

\begin{tabular}{|l|c|}
\hline \multicolumn{1}{|c|}{ Socio-demographic characteristics } & Intracapsular fractures \\
$\mathbf{N}=\mathbf{1 2}$
\end{tabular}

\section{DISCUSSION}

Failed internal fixation of neck femur fracture is considered a major problem. The problem is not only related to failure of fixation but also related to many factors affecting outcome such as poor bone quality, soft tissue condition and comorbidities of old age patients who already suffered from other diseases like DM and osteoporosis.

Secondary THA after failed internal fixation of neck femur fracture is a more difficult procedure than performing primary THA on an unoperated (virgin) hip. Associated procedures (hardware removal, fixation and osteotomy) are often required. The blood loss is greater, the intraoperative and post-operative complications rate is higher (particularly dislocation and periprosthetic fracture), and the short-term and mid-term functional outcomes are significantly worse. Pui et al. ${ }^{(7)}$ reported more complications in the THA group after nail fixation. In our study, the type of internal fixation used for the initial fracture had no effect on the postoperative complication rate or the functional outcomes.

Choice of the surgical approach is crucial. A variety of approaches were used in literature. In a recent study conducted by Mortazavi and his group ${ }^{(8)}$ studying the rates of dislocation after failed internal fixation of hip fractures in one hundred fifty-four hips. They concluded that the use of direct lateral approach is one of the major factors responsible for the absence of the postoperative dislocation recommending its use.

In our study, the lateral approach was used in all cases. Based on the computerized biomechanical model of THA after a failed plate fixation of a femoral fracture, Chen $\boldsymbol{e t} \boldsymbol{a l} .{ }^{(9)}$ suggested using a stem that bridges the last screw hole by at least $3 \mathrm{~cm}$. This principle was followed 
in our study.

Mortazavi et al. ${ }^{(8)}$ reported a mean operative time of 124 minutes and blood loss of $659 \mathrm{ml}$. Antoine Morice et al. ${ }^{(10)}$ had a mean operative time and blood loss, 98 minutes and 629 $\mathrm{ml}$ respectively. Our mean operative time and blood loss were comparable to other studies, 65 minutes and $1250 \mathrm{ml}$ respectively. The use of cementless cups in our study was consistent with most other published studies $(\mathbf{1 1}, \mathbf{1 2}$ and 13). Cemented stems were used in 4 cases (33.3\%) and cementless ones in 8 cases $(66.7 \%)$. All were standard length except for two long cementless stems. In all cases, the position of the femoral stem on an AP view was seen in neutral alignment and no patients had femoral loosening at the final follow-up.

The postoperative complications consisted of one case of dislocation that underdone revision by cementless long stem femoral component. There were no infections or periprosthetic fractures. Antonie Morice et al. (10) included postoperative complications consisted of four cases of dislocation ( 2 early and 2 late, all standard cups inserted through a posterior approach) $(6.8 \%)$ and three periprosthetic fractures at 12,35 and 72 months after the THA procedure (5\%). There were no infections ${ }^{(\mathbf{1 0})}$.

There were some limitations in our study that we were in need for a larger number of patients and a longer period of follow-up. The strengths of our study are that it was continuous, no patients were lost to follow-up, it reflected the practices of a teaching hospital.

\section{CONCLUSION}

Based on this study, THA seems to be a satisfactory salvage procedure after failed treatment of neck femur fracture. However, this is technically more difficult than routine primary total hip arthroplasty with a longer operative time and an increased incidence of intra and postoperative complications. Despite the technical challenges, in our series, there were few serious orthopedic complications and the clinical outcomes were acceptable.

\section{REFERENCES:}

1. Hopley C, Stengel D, Ekkernkamp A et al. (2010): Primary total hip arthroplasty versus hemiarthroplasty for displaced intracapsular hip fractures in older patients: systematic review. BMJ., 2332: 340-3.

2. Exaltacion J, Incavo S, Mathews V et al. (2011): Hip arthroplasty after intramedullary hip screw fixation: a perioperative evaluation. J Orthop Trauma, 23: 33-6.

3. D'Arrigo C, Perugia D, Carcangiu A et al. (2010): Hip arthroplasty for failed treatment of proximal femoral fractures. Int Orthop., 34: 939-42.

4. Zehir S, Zehir R, Zehir S (2015): Proximal femoral nail antirotation dynamic hip screw for unstable trochanteric fractures; a prospective randomized comparison. Eur J Trauma Emerg Surg., 41: 393-400.

5. Kumar P, Sen R, Aggarwal S et al. (2017): Reliability of Modified Harris Hip Score as a tool for outcome evaluation of Total Hip Replacements in Indian population. Trauma, 46 (32/4): 84-25.

6. Brooker A, Bowerman J, Robinson $\mathrm{R}$ et al. (1973): Ectopic ossification following total hip replacement. Incidence and a method of classification. J Bone Joint Surg Am., 55: 1629-32.

7. Pui C, Bostrom M, Westrich G et al. (2013): Increased complication rate following conversion total hip arthroplasty after cephalomedullary fixation for intertrochanteric hip fractures. J Arthroplasty, 28: 45-7.

8. Mortazavi S, Greenky M, Bican O et al. (2012): Total hip arthroplasty after prior surgical treatment of hip fracture: is it always challenging? The Journal of Arthroplasty, 27 (1): 31-36.

9. Chen D, Lin C, Hu C et al. (2013): Biomechanical consideration of total hip arthroplasty following failed fixation of femoral intertrochanteric fractures-A finite element analysis. Medical Engineering \& Physics, 35 (5): 569-575.

10. Morice A, Ducellier F, Bizot P (2018): Total hip arthroplasty after failed fixation of a proximal femur fracture: Analysis of 59 cases of intra-and extra-capsular fractures. Orthopaedics \& Traumatology: Surgery \& Research, 104 (5): 681686.

11. Zhang B, Chiu K, Wang $M$ (2004): Hip arthroplasty for failed internal fixation of intertrochanteric fractures. J Arthroplasty, 19: 32933.

12. Laffosse J, Molinier F, Tricoire J et al. (2007): Cementless modular hip arthroplasty as a salvage operation for failed internal fixation of trochanteric fractures in elderly patients. Acta Orthop Belg., 73: 729-33.

13. Said G, Farouk O, El-Sayed A et al. (2006): Salvage of failed dynamic hip screw fixation of intertrochanteric fractures. Injury, 37: 194-202. 